03

\title{
Фазовые переходы воды в порах цеолита
}

\author{
() Г.С. Бордонский, А.О. Орлов
}

Институт природных ресурсов, экологии и криологии СО РАН, Чита, Россия

E-mail: Igc255@mail.ru

Поступило в Редакцию 26 февраля 2018г.

В окончательной редакции 6 декабря 2018 г.

Принято к публикации 11 декабря 2018г.

\begin{abstract}
Экспериментально определены температуры фазовых переходов воды при плавлении льда в порах природного минерала цеолита с размерами пор $0.2-2 \mathrm{~nm}$. Установлены три температуры с резким изменением теплоемкости и экстремумами низкочастотных электрических флуктуаций при нагревании увлажненного материала от -150 до $100^{\circ} \mathrm{C}:-20,43$ и $86^{\circ} \mathrm{C}$. Эти значения связываются с плавлением полигональных структур, содержащих от 7 до 5 молекул воды.
\end{abstract}

DOI: 10.21883/PJTF.2019.05.47391.17265

Как известно, вода, находящаяся в поровом пространстве твердых материалов, замерзает при температурах ниже $0^{\circ} \mathrm{C}$. В случае пор нанометровых размеров переохлаждение воды может достигать $-90^{\circ} \mathrm{C}$ для размеров полостей $\sim 2 \mathrm{~nm}[1,2]$.

Вместе с тем для пор с размерами менее $2 \mathrm{~nm}$ температура переохлаждения воды в них экспериментально практически не исследована. Поэтому неожиданными оказались результаты работ [3,4]. В [3] при компьютерном моделировании состояния воды в углеродных нанотрубках обнаружено девять фаз льда, которые определялись диаметром нанотрубок в интервале $0.9-1.7 \mathrm{~nm}$ и существовали при температурах от -113 до $17^{\circ} \mathrm{C}$. В [4] при рентгеноструктурных исследованиях воды в однослойных углеродных нанотрубках были найдены различные полигональные структуры с числом молекул в них от 5 до 8 в зависимости от диаметра нанотрубок в интервале $1.1-1.7 \mathrm{~nm}$. При этом было установлено, что температура таяния ледяных структур составляла $-83,-53,7,27^{\circ} \mathrm{C}$ по мере убывания числа молекул в полигональных структурах (в сечении трубок) от 8 к 5 . Этот эффект определялся чисто геометрическими размерами пор при возникновении в них замкнутых кластеров воды в виде полигонов и трансляционным повторением их структуры вдоль оси трубки. Диаметр колец $(D)$, в которые вписаны полигоны, составлял $D=d_{0} / \sin (\pi / n)$, где $n-$ кратность полигона, $d_{0}-0.28 \mathrm{~nm}$ (расстояние между атомами кислорода). При этом разность между диаметрами нанотрубок и $D$ составляла $0.35 \mathrm{~nm}$.

Эти результаты противоречат общей, ранее установленной тенденции понижения температуры замерзания воды в порах по мере уменьшения их размеров. Исследованные в $[3,4]$ синтезированные пористые материалы имели фиксированные размеры диаметра цилиндрических пор. Возникает вопрос: наблюдается ли многообразие ледяных структур и фазовых переходов в порах природных материалов с широким распределением размеров и формы пор, особенно, при температурах выше $0^{\circ} \mathrm{C}$ в пористых средах с размерами полостей меньше $2 \mathrm{~nm}$ ?
В настоящей работе выполнено исследование температуры фазовых превращений воды в природном минерале цеолите, имеющем поры с размерами $0.2-2 \mathrm{~nm}$, в интервале от -150 до $100^{\circ} \mathrm{C}$. Для измерений использовались два метода: метод измерений собственных низкочастотных электрических флуктуаций и термометрии при равномерном нагревании (охлаждении) образцов [5]. Кроме того, для определения состояния воды в порах с размерами больше $2 \mathrm{~nm}$ измерялось затухание микроволнового излучения в среде аналогично [6]. Схема установки для одновременного проведения тепловых и электрических измерений приведена на рис. 1. Исследовался порошкообразный цеолит из Шивыртуйского месторождения, расположенного в Забайкальском крае. Размер гранул материала $\sim 70 \mu \mathrm{m}$. Состав минералов в образцах был следующим: $\sim 90 \%$ клиноптилолита, остальные 10\% - монтмориллонит с примесью кварца, полевых шпатов и слоистых силикатов. Удельная поверхность пор $\sim 100 \mathrm{~m}^{2} / \mathrm{g}$, объем пор $\sim 0.1 \mathrm{~cm}^{3} / \mathrm{g}$, размеры мелких пор составляли от 0.2 до $2 \mathrm{~nm}$ [7]. Весовая влажность исследованных образцов имела значение около $10 \%$.

Термометрия образцов проводилась путем их нагревания от комнатной температуры до $100^{\circ} \mathrm{C}$ с последующим охлаждением до $-150^{\circ} \mathrm{C}$. Холодные образцы вторично нагревались до $100^{\circ} \mathrm{C}$. Нагрев и охлаждение проводились при фиксированных значениях подвода (отвода) тепла от нагревателя и охлаждающего газа из сосуда Дьюара с жидким азотом. Время нагревания и охлаждения в интервале от 100 до $-150^{\circ} \mathrm{C}$ около $2 \mathrm{~h}$. Точность определения температуры $1{ }^{\circ} \mathrm{C}$.

Результаты температурных измерений в виде зависимости производной температуры цеолита $(T)$ по времени $(t)$ для одного из исследованных образцов при его нагревании приведены на рис. 2,a. На рис. 2, $b$ представлены результаты измерений амплитуды шумов на выходе усилителя для того же образца.

Как видно из рис. 2, $a$, выявляются три наиболее выраженных фазовых перехода первого рода с поглощением тепла в процессе нагревания цеолита при 


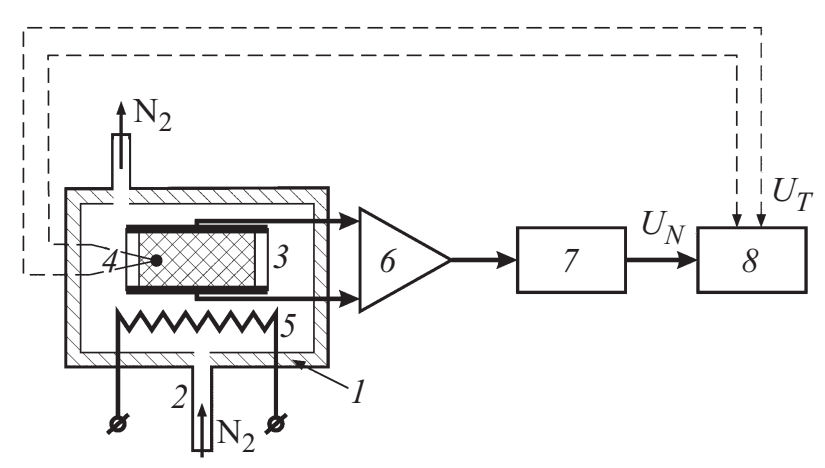

Рис. 1. Схема установки для исследования фазовых переходов воды в цеолите. 1 - термостат, 2 - трубка для подачи холодных паров азота, 3 - ячейка с порошком цеолита, 4 - термопара для измерения температуры среды, 5 нагреватель термостата, 6 - низкочастотный усилитель с полосой $100 \mathrm{~Hz}-1 \mathrm{kHz}$, входным сопротивлением $4.7 \mathrm{M} \Omega$ и коэффициентом усиления $10^{3}, 7-$ детектор амплитуды и интегратор с постоянной времени $1 \mathrm{~s}, 8-$ система сбора информации Agilent. $U_{T}-$ напряжение термопары, $U_{N}-$ напряжение, пропорциональное среднему значению амплитуды шума в полосе частот усилителя.

температурах $-20,43$ и $86^{\circ} \mathrm{C}$. Следует отметить, что при измерении затухания микроволнового излучения на частоте $34 \mathrm{GHz}$ при охлаждении цеолита, помещенного в волновод, было установлено плавное его уменышение при температурах ниже $-40^{\circ} \mathrm{C}$. Это указывает на непрерывное замерзание кластеров воды в порах и пространстве между гранулами с размерами более $2 \mathrm{~nm}$ при температурах от 0 до $-90^{\circ} \mathrm{C}$. Такое же плавное изменение фазового состояния наблюдалось при нагревании образца, что приводило к отсутствию резких изменений $d T / d t$ в области от -150 до $-40^{\circ} \mathrm{C}$. При оценках температур таяния воды в порах с размерами более $2 \mathrm{~nm}$ использованы результаты [1,2], которые представляли собой непрерывное распределение в интервале от -90 до $-5^{\circ} \mathrm{C}$.

При измерениях амплитуды низкочастотных шумов были выявлены области температур с резким их возрастанием, совпадающие с минимумами $d T / d t$ при 43 и $86^{\circ} \mathrm{C}$. Экстремум шумов при $43^{\circ} \mathrm{C}$ наблюдался при первоначальном нагревании образца от комнатной температуры до $100^{\circ} \mathrm{C}$, при последующем нагревании от $-150^{\circ} \mathrm{C}$ экстремум имел место при $86^{\circ} \mathrm{C}$ (рис. 2,b). Наличие выраженных экстремумов электрических флуктуаций, а также их гистерезис можно связать с фазовыми переходами при образовании (разрушении) сегнетоэлектрических фаз воды (льда) [5,8]. Обнаружение трех значений температур фазовых переходов, как представляется, связано с образованием полигональных структур в порах подходящих для них размеров при изменении температуры воды. Предполагаемые значения размеров пор и температур, при которых происходит разрушение кластеров с $n$-полигонами, по аналогии с данными работы [4] представлены на рис. 3. В [4] эти полигональные структуры, состоящие из молекул воды с числом от 8 до 5, были обнаружены в углеродных нанотрубках при рентгеноструктурных исследованиях.

Таким образом, в природном цеолите, имеющем набор пор малого размера от 0.2 до $2 \mathrm{~nm}$, наблюдалось несколько фазовых переходов в интервале температур от -20 до $86^{\circ} \mathrm{C}$ в отличие от одного фазового перехода в порах с размерами более $2 \mathrm{~nm}[1,2]$ в случае их фиксированных значений.

По данным термометрии в исследуемом цеолите обнаружены температуры фазовых переходов с поглощением тепла при нагревании образцов (после их предварительного охлаждения до $\left.-150^{\circ} \mathrm{C}\right)$ при -20 , 43 и $86^{\circ} \mathrm{C}$. По данным электрических низкочастотных шумовых измерений экстремумы шумов наблюдались при температурах 43 и $86^{\circ} \mathrm{C}$, что может быть связано с появлением сегнетоэлектрических фаз, т.е. фазовым переходом второго рода. Таким образом, переходы при 43 и $86^{\circ} \mathrm{C}$ являются фазовыми переходами смешанного типа.

Наличие фазовых переходов при положительных температурах соответствует результатам ранее выполненных рентгеноструктурных исследований воды в однослойных углеродных нанотрубках с фиксированным значением диаметра в интервале $1.1-1.7 \mathrm{~nm}$ [4]. В случае цеолита можно предположить аналогичную ситуацию с некоторым сдвигом температур фазовых переходов из-за другой геометрии порового пространства.

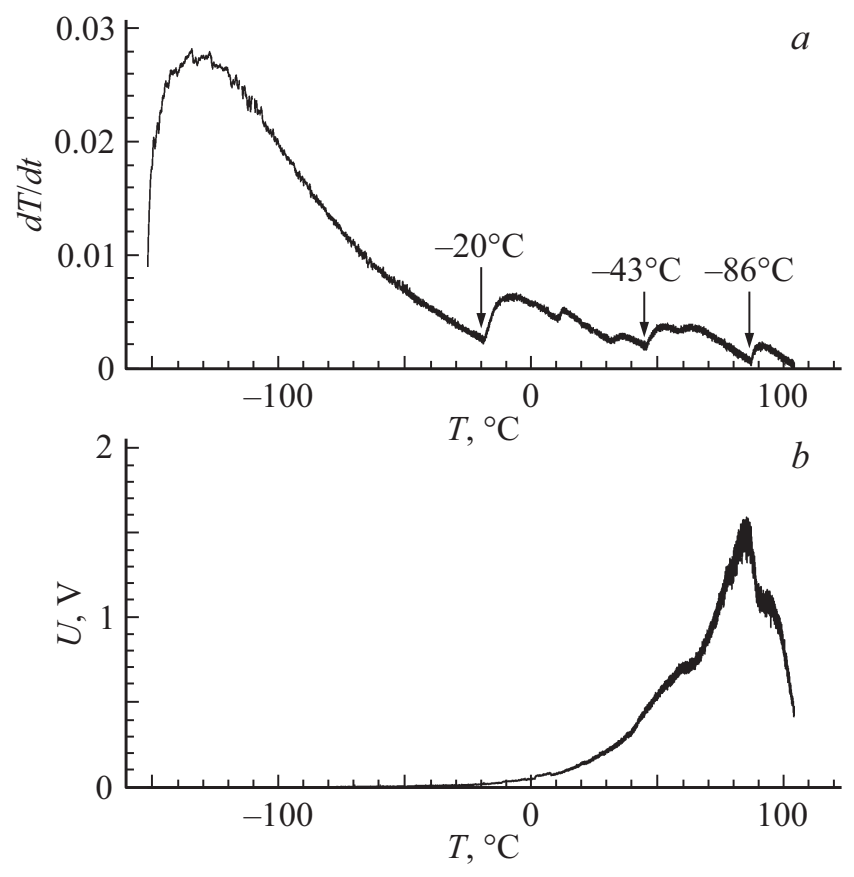

Рис. 2. Результаты измерений при нагревании ячейки с образцом цеолита с весовой влажностью $3 \%$ от $-150^{\circ} \mathrm{C}$. $a$ - температурная зависимость производной температуры по времени $(d T / d t) ; b-$ температурная зависимость среднего значения амплитуды низкочастотных электрических шумов на выходе усилителя. Стрелками отмечены температуры, при которых наблюдались фазовые переходы воды с поглощением тепла. 


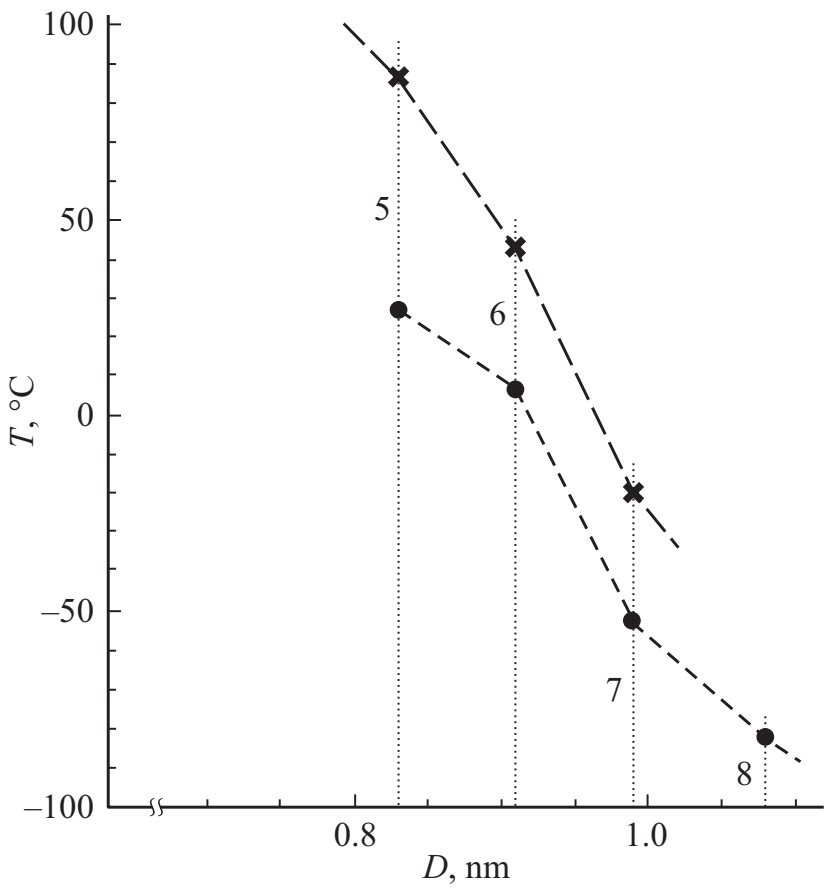

Рис. 3. Связь температур полигональных структур, при которых происходит их плавление, с размерами пор. Кружки результаты, представленные в работе [4] для углеродных нанотрубок фиксированного диаметра. Крестики - предполагаемые значения связи обнаруженных температур фазовых переходов в цеолите с размером пор. Пунктирными линиями и цифрами около них отмечено число молекул в полигонах в области фазового перехода от ледяных структур к жидкости.

Как представлено в [4], кольцевые структуры трубчатого льда с числом молекул от 4 до 8 в сечении могут стабилизироваться из-за малого диаметра нанотрубок. В случае цеолита с широким распределением размеров и геометрией пор в виде полостей, соединенных каналами, наблюдаемый фазовый переход при $-20^{\circ} \mathrm{C}$ можно соотнести с плавлением гептагона (т.е. колец с семью молекулами); для температуры $43^{\circ} \mathrm{C}-$ это разрушение гексагона; для $86^{\circ} \mathrm{C}$ - таяние структуры с пятью молекулами воды.

Общий вывод - свойства воды в порах с размерами менее $2 \mathrm{~nm}$ существенно отличаются от свойств воды в порах больших размеров. Обнаруживается несколько фазовых переходов ледяных структур до температур, достигающих $80-90^{\circ} \mathrm{C}$. Данная особенность проявилась в природном минерале с широким набором размеров пор $(0.2-2 \mathrm{~nm})$.

\section{Список литературы}

[1] Limmer D.T., Chandler D. // J. Chem. Phys. 2012. V. 137. N 4. P. 044509.

[2] Меньшиков Л.И., Меньшиков П.Л., Федичев П.О. // ЖЭТФ. 2017. Т. 152. B. 6. C. $1374-1392$.

[3] Takaiwa D., Hatano I., Koga K., Tanaka H. // PNAS. 2008. V. 105. N 1. P. 39-43.
[4] Maniwa Y., Kataura H., Abe M., Udaka A., Suzuki Sh., Achiba Y., Kira H., Matsuda K., Kadowaki H., Okabe Y. // Chem. Phys. Lett. V. 401. N 4-6. P. 534-538.

[5] Бордонский Г.С., Орлов А.О. // ФТТ. 2014. Т. 56. В. 8. C. $1575-1582$

[6] Бордонский Г.С., Гурулев А.А. // Письма в ЖТФ. 2017. Т. 43. B. 8. C. $34-40$.

[7] Эпова Е.С., Еремин О.В., Бычинский В.А. О возможности использования природных цеолитов для очистки питьевых вод // Всерос. конф. с международным участием „Эволюция биосферы и техногенез“. Чита: Изд-во БНЦ СО РАН, 2016. C. 137-139.

[8] Бордонский Г.С., Орлов А.О. // Криосфера Земли. 2017. T. XXI. № 6. C. 45-54. 